\title{
Diversidade genética de estoques de reprodutores de Colossoma macropomum
}

\author{
[Genetic diversity of Colossoma macropomum broodstocks]
}

\author{
T.S. Lopes ${ }^{1}$, D.P. Streit Jr. ${ }^{2}$, R.P. Ribeiro ${ }^{1}$, J.A. Povh ${ }^{1}$, N.M. Lopera-Barrero ${ }^{1}$, L. Vargas ${ }^{1}$, \\ C. Pinto Filho ${ }^{3}$, J.R. Queiroz ${ }^{3}$ \\ ${ }^{1}$ Centro de Ciências Agrárias - UEM \\ Av. Colombo, 5790 \\ 87020-900 - Maringá, PR \\ ${ }^{2}$ Universidade Federal do Rio Grande do Sul - Porto Alegre, RS \\ ${ }^{3}$ SEAPES - Porto Velho, RO
}

\begin{abstract}
RESUMO
Analisou-se a diversidade genética de estoques de reprodutores de Tambaqui (Colossoma macropomum), mediante o uso de marcador RAPD, utilizando-se 10 primers para analisar 30 amostras do estoques de reprodutores das pisciculturas de Boa Esperança e Vale Verde, localizadas no Estado de Rondônia. A porcentagem de fragmentos polimórficos e o índice de diversidade genética de Shannon foram altos nos dois estoques de reprodutores. O estoque de reprodutores de Boa Esperança apresentou um fragmento exclusivo. A diferenciação genética foi baixa e o número de migrantes por geração foi alto entre os estoques de reprodutores. O dendrograma não separou os indivíduos dos estoques de reprodutores em grupos distintos. Há alta variabilidade genética nos estoques de reprodutores, um pouco inferior no estoque de Vale Verde, e há grande proximidade genética entre os indivíduos dos estoques de reprodutores.
\end{abstract}

Palavras-chave: tambaqui, Colossoma macropomum, RAPD, variabilidade genética, monitoramento genético

\begin{abstract}
The genetic diversity of tambaqui (Colossoma macropomum) broodstocks from two hatchery station in Rondonia State was studied by the RAPD marker. Ten primers were used to analyze 30 broodstocks samples from the hatchery stations of Boa Esperança and Vale Verde. The polymorphic fragments percentage and Shannon genetic diversity index were high in the two broodstocks. The Boa Esperança broodstock presented an exclusive fragment. The genetic differentiation was low and the number of migrants per generation was high among the broodstocks. The dendrogram did not separate the broodstocks individuals in different groups. The results indicate a high genetic variability in the broodstocks, being a little bit lower in the Vale Verde broodstock. Besides, there is a genetic proximity among the broodstocks.
\end{abstract}

Keywords: tambaqui, Colossoma macropomum, RAPD, genetic variability, genetic monitoring

\section{INTRODUÇÃO}

A espécie Colossoma macropomum, conhecida como tambaqui, ocorre naturalmente nas bacias dos rios Amazonas e Orinoco (Araújo-Lima e Gomes, 2005) e representa a maior produção entre as espécies nativas, com $14,0 \%$ do total de peixes produzidos no Brasil, superada somente pelas espécies exóticas tilápia (Oreochromis niloticus), com 38,2\%, e carpa (Cyprinus carpio), com 25,0\% (Recursos..., 2005). No Estado de Rondônia, C. macropomum é a principal espécie, e das 4.151 ton. de peixes produzidas neste Estado, 3.350 ton. são somente dessa espécie. Segundo Streit Jr. (2005), 73\% dos 5.730.000 alevinos produzidos no ano de

Recebido em 12 de fevereiro de 2008

Aceito em 20 de fevereiro de 2009

E-mail: tais.peixegen@gmail.com 
2005 são dessa espécie. O autor relaciona ainda que, do total de 4.182.900 de alevinos de $C$. macropomum produzidos no ano de 2005, 95,6\% foram resultantes de apenas três pisciculturas, localizadas nos municípios de Porto Velho, Ouro Preto do Oeste e Pimenta Bueno.

Tendo como base a importância econômica nacional e regional, a espécie $C$. macropomum foi incluída no programa brasileiro de melhoramento genético, coordenado por várias instituições de pesquisas (oito unidades da Embrapa, dez universidades federais, três estaduais, uma universidade norte-americana e centros de pesquisa e iniciativa privada), juntamente com o pintado (Pseudoplatystoma corruscans), o camarão branco (Litopenaeus vannamei) e a tilápia (O. niloticus). A partir desse programa, começarão a ser desenvolvidas, em várias regiões do país, pesquisas que irão estudar, pela primeira vez, o melhoramento genético na aquicultura brasileira (Produção..., 2007).

A variabilidade genética é fundamental para qualquer programa de melhoramento genético (Falconer, 1987) e, dessa forma, a identificação do nível de variabilidade nos estoques de reprodutores é importante para iniciar um programa de melhoramento genético. Isso porque a diminuição da variabilidade genética promove a perda do potencial no melhoramento genético (Melo et al., 2006; Moreira et al., 2007). Além disso, o recente projeto de construção de barragem para geração de energia elétrica no rio Madeira, em Rondônia, possivelmente estimulará a implantação de programas de aumento de estoque de peixes para contornar os efeitos adversos na ictiofauna e, dessa forma, a conservação da variabilidade genética, que é fundamental para a viabilidade desses programas, e para evitar os impactos negativos na ictiofauna (Sirol e Britto, 2006).

Devido à importância da variabilidade genética em programas de melhoramento e de aumento de estoques de peixes, o monitoramento genético dos estoques de reprodutores é fundamental, e a utilização dos marcadores moleculares como ferramenta para esse propósito tem se mostrado eficiente (Wasko et al., 2004; Barroso et al., 2005; Hisdorf et al., 2006).
O objetivo deste estudo foi analisar a diversidade genética do estoque de reprodutores de $C$. macropomum de duas pisciculturas do Estado de Rondônia, mediante o marcador RAPD.

\section{MATERIAL E MÉTODOS}

As amostras foram obtidas dos estoques de reprodutores de C. macropomum da piscicultura Vale Verde, Pimenta Bueno (latitude 11\%40'21"S, longitude $\left.61^{\circ} 11^{\prime} 37^{\prime \prime} \mathrm{O}\right)$, e da piscicultura Boa Esperança, Ouro Preto do Oeste (latitude $10^{\circ} 44^{\prime} 53^{\prime \prime S}$, longitude 62¹2'57"O), ambas no Estado de Rondônia (Fig. 1). Embora os estoques de reprodutores possam ter sido formados por peixes capturados do rio Guaporé, não existe registro sobre a origem nas pisciculturas.

Foram colhidas 30 amostras de nadadeira caudal de cada um dos estoques de reprodutores. A extração do DNA foi realizada segundo a metodologia modificada por Povh et al. (2006). O DNA foi quantificado por comparação com concentrações de DNA fago $\lambda$ em gel de agarose $1 \%$, sendo a eletroforese conduzida com tampão 1X TAE (40mM de Tris-acetato e $1 \mathrm{mM}$ de EDTA) por uma hora a 70 volts.

O DNA foi amplificado em um volume de reação de $15 \mu \mathrm{L}$, no qual se utilizaram tampão $1 \mathrm{X}$ Tris$\mathrm{KCl}, 2,0 \mathrm{mM}$ de $\mathrm{MgCl}_{2}, 0,46 \mu \mathrm{M}$ de primer, $0,2 \mathrm{mM}$ de cada dNTP, uma unidade de Taq DNA Polimerase e 10ng de DNA. O DNA foi desnaturado a $94^{\circ} \mathrm{C}$ por quatro minutos e, em seguida, foram realizados 40 ciclos, cada um consistindo de um minuto de desnaturação a $94^{\circ} \mathrm{C}$, um minuto e 30 segundos de anelamento a $40^{\circ} \mathrm{C}$ e dois minutos de extensão a $72^{\circ} \mathrm{C}$. Posteriormente aos ciclos, foi realizada uma extensão final a $72^{\circ} \mathrm{C}$ por sete minutos. As reações foram amplificadas em termociclador Eppendorf Mastercycler Gradient, sendo avaliados 60 primers do kit OPA, OPX e OPW da Operon ${ }^{1}$, dos quais foram selecionados os que apresentaram bandas consistentes e reproduzíveis. A eletroforese foi realizada em tampão $0,5 \mathrm{X}$ TBE (45mM de Tris-Borato e $1 \mathrm{mM}$ de EDTA) por quatro horas a 70 volts.

\footnotetext{
${ }^{1}$ Operon Technologies Inc. - Alameda, Ca, EUA.
} 


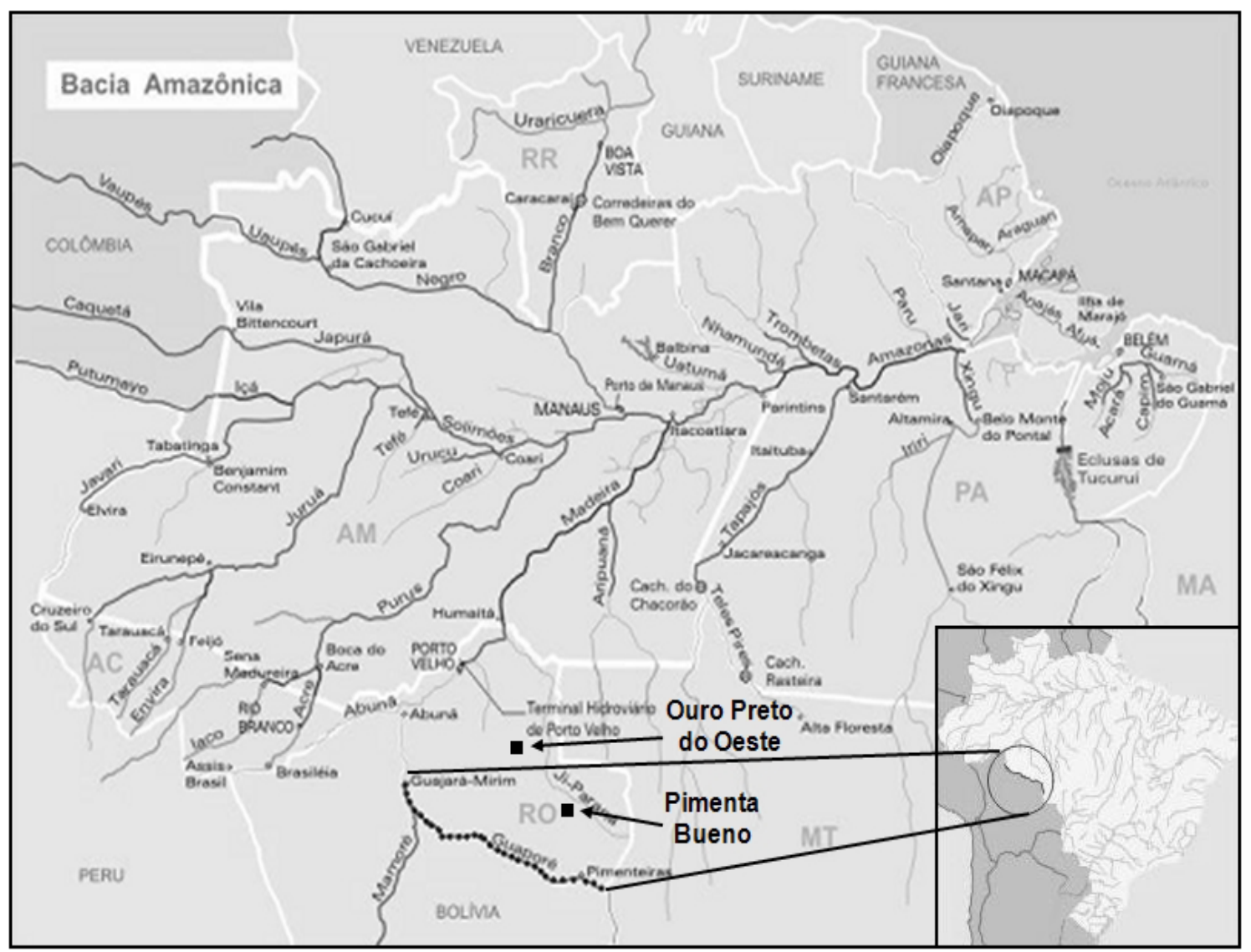

Figura 1. Localização dos municípios de Pimenta Bueno e Ouro Preto do Oeste, Rondônia, onde se encontram as pisciculturas de Boa Esperança e Vale Verde, respectivamente. Na figura, destaca-se o rio Guaporé, possível origem dos estoques de reprodutores.

Os géis utilizados para quantificação do DNA e verificação dos produtos de amplificação foram visualizados sob radiação UV após exposição destes ao brometo de etídio $\left(0,5 \mu \mathrm{g} \mathrm{mL}^{-1}\right)$ por uma hora. Posteriormente, a imagem dos géis foi fotografada com o programa Kodak EDAS-290 (Kodak 1D Image Analysis 3.5). Este mesmo programa foi utilizado para estimar o tamanho dos fragmentos amplificados a partir do marcador $100 \mathrm{pb}$ DNA ladder.

A variabilidade genética foi estimada pelo índice de diversidade genética de Shannon e pela porcentagem de fragmentos polimórficos utilizando-se o programa POPGENE 1.31 (Yeh et al., 1999). Este programa também foi utilizado para determinar a diferenciação genética $\left(G_{\mathrm{ST}}\right)$ entre os indivíduos dos estoques de reprodutores, sendo sua significância testada pelo teste $\chi^{2}$, e para determinar o número de migrantes por geração $(\mathrm{Nm})$. As frequências dos fragmentos entre os indivíduos dos estoques reprodutores foram análisadas pelo teste exato (Raymond e Rousset, 1995) utilizando-se o programa TFPGA 1.3 (Miller, 1997). A fim de representar graficamente a similaridade genética, utilizou-se o programa NTSYS 1.7 (Rohlf, 1989) para construir um dendrograma com base no coeficiente de Jaccard e com o algoritmo de agrupamento UPGMA (Unweighted Pair-Group Method Using an Arithmetic Average).

\section{RESULTADOS E DISCUSSÃO}

Os 10 primers amplificados nas amostras dos estoques de reprodutores de C. macropomum das Pisciculturas de Boa Esperança e de Vale Verde produziram 100 fragmentos (9 a 12 por primer) com tamanho entre $100 \mathrm{pb}$ a $2500 \mathrm{pb}$ (Tab. 1$)$. 
Diversidade genética de estoques...

Tabela 1. Sequência dos primers, número e tamanho dos fragmentos obtidos com a amplificação das amostras dos estoques de reprodutores de Colossoma macropomum

\begin{tabular}{cccc}
\hline Primer & $\begin{array}{c}\text { Sequência de nucleotídeos } \\
\left(5^{\prime} \rightarrow 3^{\prime}\right)\end{array}$ & $\begin{array}{c}\mathrm{N}^{\mathrm{o}} \text { de } \\
\text { fragmentos }\end{array}$ & $\begin{array}{c}\text { Tamanho dos fragmentos } \\
(\mathrm{pb})\end{array}$ \\
\hline OPA01 & CAG GCC CTT C & 12 & $330-2.500$ \\
OPA02 & TGC CGA GCT G & 12 & $220-1.950$ \\
OPA16 & AGC CAG CGA A & 10 & $400-2.400$ \\
OPW01 & CTC AGT GTC C & 10 & $600-1.900$ \\
OPW02 & ACC CCG CCA A & 8 & $500-2.400$ \\
OPW03 & GTC CGG AGT G & 9 & $340-2.300$ \\
OPW08 & GAC TGC CTC T & 9 & $470-1.990$ \\
OPW19 & CAA AGC GCT C & 10 & $400-2.200$ \\
OPX01 & CTG GGC ACG A & 11 & $100-1.800$ \\
OPX02 & TTC CGC CAC C & 9 & $700-2.200$ \\
\hline Total & - & 100 & $100-2.500$ \\
\hline
\end{tabular}

Oito dos 100 fragmentos analisados apresentaram diferença significativa na frequência entre os estoques de reprodutores (Tab. 2). O estoque de reprodutores da piscicultura de Boa Esperança apresentou um fragmento exclusivo de $1.370 \mathrm{pb}$ e quatro de maior frequência. $\mathrm{O}$ estoque de reprodutores da piscicultura Vale Verde apresentou três fragmentos de maior frequência. A eliminação de um fragmento e a baixa frequência do fragmento de $1.750 \mathrm{pb}(0,0742)$ no estoque de reprodutores desta última piscicultura, indicam menor variabilidade genética deste em relação ao estoque de reprodutores de Boa Esperança.

O índice de diversidade genética de Shannon e a porcentagem de fragmentos polimórficos foram de 0,469 e $77,0 \%, 0,440$ e $75,0 \%$ para os estoques de reprodutores das piscicultura Boa Esperança e Vale Verde, respectivamente. Assim como a análise dos fragmentos, estes resultados mostram menor variabilidade genética no estoque de reprodutores de Vale Verde.

Tabela 2. Caracterização, tamanho e frequência dos fragmentos que apresentaram valores significativos pelo teste exato $(\mathrm{P}<0,05)$ entre os estoques de reprodutores de Colossoma macropomum de Boa Esperança e Vale Verde

\begin{tabular}{ccccc}
\multirow{2}{*}{ Primer } & \multirow{2}{*}{ Tamanho $(\mathrm{pb})$} & \multicolumn{2}{c}{ Frequência dos fragmentos } & \multirow{2}{*}{ P-valor } \\
\cline { 3 - 4 } & & Boa Esperança & Vale Verde & 0,0014 \\
OPA16 & 1.800 & 0,7418 & 0,3417 & 0,0189 \\
OPX02 & 2.200 & 0,1835 & 0,4226 & 0,0043 \\
OPW03 & 1.250 & 0,7643 & 0,2662 & 0,0000 \\
OPW01 & 600 & 0,5451 & 0,1340 & 0,0116 \\
OPW01 & 1.370 & 0,1290 & 0 & 0,0365 \\
OPW01 & 1.750 & 0,2344 & 0,0742 & 0,0116 \\
OPX01 & 1.150 & 0,4429 & 0,8110 & 0,0111 \\
OPX02 & 1.950 & 0,4429 & 0,8110 & \\
& & & & \\
\hline
\end{tabular}


Embora a diversidade genética seja bastante variável conforme a espécie, o local de captura dos peixes e as pressões existentes em cada ambiente, os dois estoques de reprodutores estudados apresentaram valores superiores de variabilidade genética em relação a outras espécies da mesma família Characidae, como é o caso de populações nativas de Pimelodus maculatus do Rio Paranapanema e Tietê (Almeida et al., 2003), e de populações nativas de Astyanax altiparanae do Rio Paranapanema (Leuzzi et al., 2004). Da mesma forma que o presente estudo, Santos et al. (2007), ao estudarem o DNA mitocondrial, já haviam considerado como alta a variabilidade genética de populações nativas de $C$. macropomum de localidades do rio Amazonas.

O nível de variabilidade genética dos estoques de reprodutores depende da origem, do número de reprodutores utilizados, do manejo reprodutivo adotado e da diversidade genética dos peixes que formaram $o$ estoque. Estes mesmos fatores podem justificar a diferença de variabilidade genética observada entre os dois estoques de reprodutores. Contudo, não é possível fazer inferências com relação a isso, visto que não há registro sobre a formação desses estoques. A alta diversidade genética dos estoques de reprodutores é extremamente importante. No entanto, produzir peixes jovens com essa característica não depende apenas dessa condição. $\mathrm{O}$ inadequado manejo reprodutivo pode promover diminuição da variabilidade genética (Moreira et al., 2007), e em apenas uma geração (Porta et al., 2006).

A endogamia, utilização de um pequeno número de reprodutores, e a seleção não intencional durante a reprodução (escolha de reprodutores sem pretensões de melhoramento genético, como, por exemplo, de peixes maiores ou menores, a não utilização de todo o período reprodutivo) são os principais fatores do manejo reprodutivo que promovem a diminuição da variabilidade genética. Portanto, o monitoramento genético dos estoques de reprodutores é de grande importância para a manutenção da diversidade genética, visto que a diminuição deste parâmetro tende a limitar o potencial de ganho no melhoramento genético
(Povh et al., 2005; Melo et al., 2006; Moreira et al., 2007) e a afetar diretamente a viabilidade (sobrevivência no ambiente aquático) dos peixes jovens dos programas de aumento de estoques de peixes.

A alta prolificidade dos peixes reofílicos, como é o caso da espécie $C$. macropomum, tende a favorecer os fatores do manejo reprodutivo que conduzem à diminuição da variabilidade genética. Sendo assim, é fundamental o adequado manejo genético dos reprodutores, e o monitoramento mediante os marcadores moleculares é ferramenta adequada para este propósito. Contudo, considerando que essa perda da diversidade genética é irreversível, podendo ser recuperada somente com a introdução de um novo material genético (Yokota et al., 2003; Sekino et al., 2004), uma forma de aumentar a variabilidade genética no estoque de reprodutores é a introdução de novos indivíduos.

A diferenciação genética de 0,0361 entre os estoques de reprodutores de pisciculturas de Boa Esperança e Vale Verde foi baixa segundo a definição de Wright (1978). Isso mostra grande proximidade genética entre os estoques de reprodutores. Segundo Araújo-Lima e Goulding (1998), a maioria dos estoques de reprodutores de C. macropomum das pisciculturas de Rondônia não foram formados por um grande número de reprodutores, situação que pode ter favorecido a troca de reprodutores entre estas pisciculturas, o que justificaria a baixa diferenciação genética e o alto número de migrantes por geração $(\mathrm{Nm})$ obtidos entre os estoques de reprodutores, que foi de 13,35. Outra hipótese é que a origem dos estoques de reprodutores tenha sido a mesma, possivelmente por peixes capturados do rio Guaporé, o que justificaria a baixa diferenciação genética e o alto número de migrantes por geração. Contudo, não existem registros para confirmar tais hipóteses.

O dendrograma mostra que os estoques de reprodutores não formaram grupos distintos, e, assim como a análise da diferenciação genética e o $\mathrm{Nm}$, indica grande proximidade genética entre os indivíduos dos estoques de reprodutores (Fig. 2). 


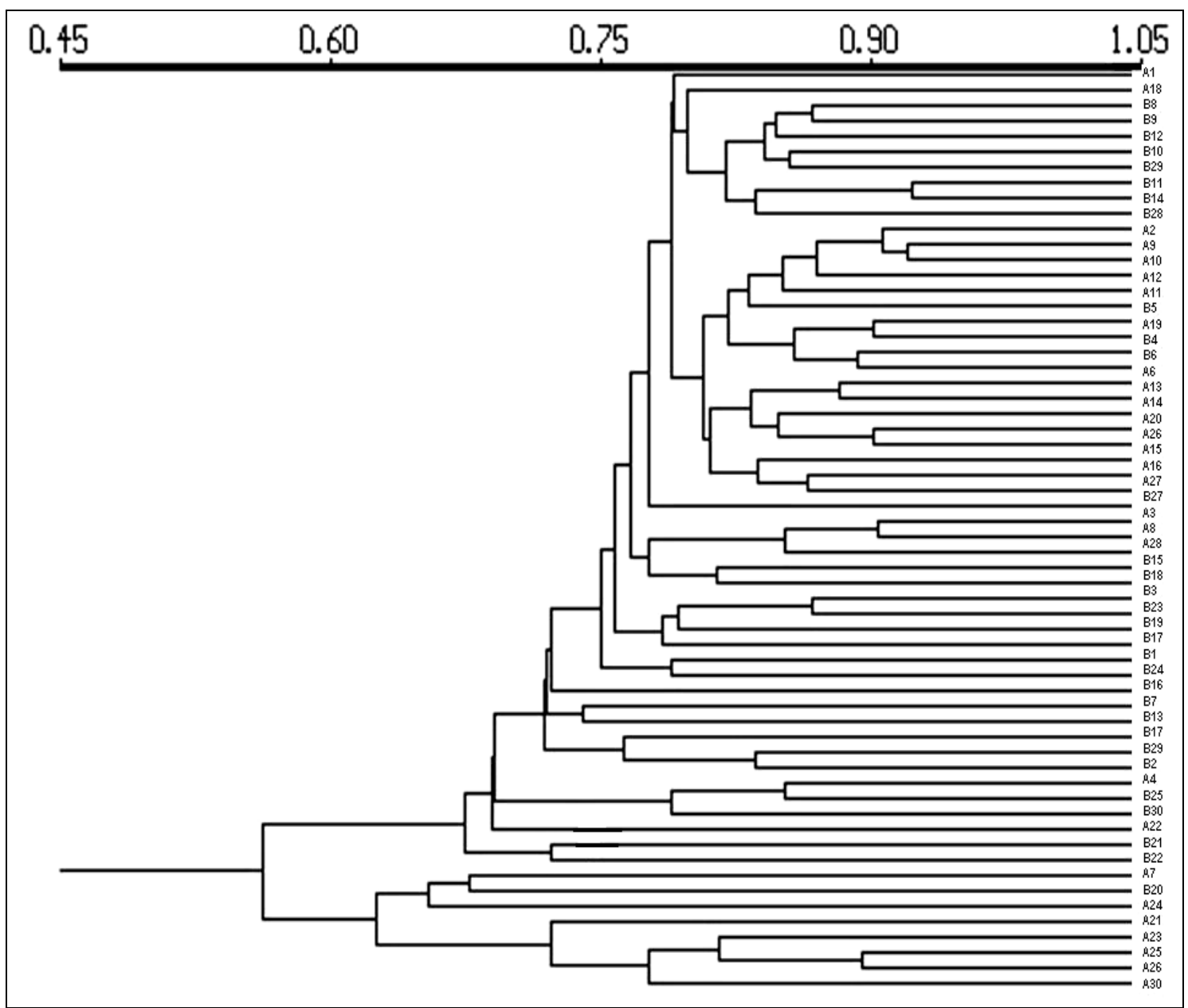

Figura 2. Dendrograma mostrando a similaridade genética entre os indivíduos dos estoques de reprodutores de Colossoma macropomum. A: Estoque de reprodutores da piscicultura Boa Esperança, Ouro Preto do Oeste, RO; B: Estoque de reprodutores da piscicultura Vale Verde, Pimenta Bueno, RO.

Com a construção de barragem para geração de energia elétrica no rio Madeira, possivelmente surgirão programas de aumento de estoque de peixes para contornar os efeitos adversos que estas proporcionam nas populações de peixes nativos, como aconteceu em vários rios brasileiros. Contudo, vários desses programas são realizados sem respaldo científico (Agostinho et al., 2005). Tendo em vista que a diminuição da variabilidade genética pode tornar o programa de repovoamento ineficiente (baixa sobrevivência dos peixes jovens no ambiente aquático) e proporcionar impactos genéticos irreversíveis na população nativa, o monitoramento genético dos estoques de reprodutores, assim como dos peixes jovens que serão soltos nos rios, é fundamental para estes programas.
Este estudo fornece informações sobre a diversidade genética de dois estoques de reprodutores das pisciculturas que são responsáveis por $65 \%$ dos alevinos produzidos no Estado de Rondônia. Estes dados são úteis para futuros programas de melhoramento genético e também de conservação da diversidade genética. $\mathrm{O}$ marcador molecular RAPD, além de ser uma ferramenta eficiente para estimar o nível de diversidade genética dos estoques de reprodutores, também pode auxiliar o manejo reprodutivo, evitando a diminuição da variabilidade genética, mediante a identificação dos reprodutores mais divergentes geneticamente, permitindo maximizar a variabilidade genética e minimizar o nível de endogamia e também do afunilamento genético 
(efeito bottleneck) nas próximas gerações. Contudo, embora envolva um maior custo, o marcador molecular microssatélite, desenvolvido para Piaractus mesopotamicus e testado para $C$. macropomum por Calcagnotto et al. (2001), é outra opção eficiente para estes propósitos, o qual pode fornecer um maior número de informações por ser um marcador codominante.

\section{CONCLUSÕES}

A variabilidade genética dos estoques de reprodutores de C. macropomum de Boa Esperança e Vale Verde é alta, um pouco no estoque de reprodutores de Boa Esperança. A diferenciação genética entre os dois estoques de reprodutores é baixa.

\section{REFERÊNCIAS BIBLIOGRÁFICAS}

AGOSTINHO, A.A.; THOMAZ, S.M.; GOMES, L.C. Conservação da biodiversidade em águas continentais do Brasil. Megadiversidade, v.1, p.70-78, 2005.

ALMEIDA, F.S.; SODRÉ, L.M.K.; CONTEL, E.P.B. Population structure analysis of Pimelodus maculatus (Pisces, Siluriformes) from the Tietê and Paranapanema Rivers (Brazil). Genet. Mol. Biol., v.26, p.301-305, 2003.

ARAUJO-LIMA， C.A.R.M.; GOMES， L.C. Tambaqui (Colossoma macropomum) In: BALDISSEROTTO, B.; GOMES, L.C. (Eds). Espécies nativas para piscicultura no Brasil. Santa Maria: UFSM, 2005. p.67-104.

ARAÚJO-LIMA，C.A.R.M.; GOULDING，M. Os frutos do tambaqui. Ecologia, conservação e cultivo na Amazônia. São Paulo: Lithera Maciel Editora Gráfica, 1998. 186p.

BARROSO, R.M.; HILSDORF, A.W.S.; MOREIRA, H.L.M. et al. Genetic diversity of wild and cultured populations of Brycon opalinus (Cuvier, 1819) (Characiforme, Characidae, Bryconiae) using microsatellites. Aquaculture, v.247, p.51-65, 2005 .

CALCAGNOTTO D.; RUSSELlO, M.; DESALLE, R. Isolation and characterization of microsatellite loci in Piaractus mesopotamicus and their applicability in other Serrasalminae fish. Mol. Ecol. Notes, v.1, p.245-247, 2001.

FALCONER, D.S. Introdução a genética quantitativa. Viçosa: UFV, 1987. 279 p.
HILSDORF, A.W.S.; RESENDE, E.K.; MARQUES, D.K.S. Genética e conservação de estoques pesqueiros de águas continentais no Brasil: situação atual e perspectivas. Corumbá: Embrapa Pantanal, 2006. 44p.

RECURSOS pesqueiros: Estatística pesqueira, 2005. Brasília: IBAMA. Disponível em: $<$ http://www.ibama.gov.br/>. Acessado em: 1 out. 2007.

LEUZZI, M.S.P.; ALMEIDA, F.S.; ORSI, M.L. et al. Analysis by RAPD of the genetic structure of Astyanax altiparanae (Pisces, Characiformes) in reservoirs of the River Paranapanema. Genet. Mol. Biol., v.27, p.355-362, 2004.

MELO, D.C.; OLIVEIRA, D.A.A.; RIBEIRO, L.P. et al. Caracterização genética de seis plantéis comerciais de tilápia (Oreochromis) utilizando marcadores microssatélites. Arq. Bras. Med. Vet. Zootec., v.58, p.87-93, 2006.

MILLER, M.P. Tools for population genetic analyses (TFPGA) 1.3: A Windows program for the analysis of allozyme and molecular population genetic data. Logan: Utah State University, 1997.

MOREIRA, A.A.; HILSDORF, A.W.S.; SILVA, J.V. et al. Variabilidade genética de duas variedades de tilápia nilótica por meio de marcadores microssatélites. Pesq. Agropec. Bras., v.42, p.521-526, 2007.

PORTA, J.; PORTA, J.M.; MATÍNEZRODRÍGUEZ, G. et al. Genetic structure and genetic relatedness of a hatchery stock of Senegal sole (Solea senegalensis) inferred by microsatellites. Aquaculture, v.251, p.46-55, 2006.

POVH, J.A.; MOREIRA, H.L.M.; RIBEIRO, R.P. et al. Estimativa da variabilidade genética em tilápia do Nilo (Oreochromis niloticus) com a técnica de RAPD. Acta Sci. Anim. Sci., v.27, p.1$10,2005$.

POVH, J.A.; RIBEIRO, R.P.; MANGOLIN, C.A. et al. Padronização de protocolo de extração de DNA de pacu (Piaractus mesopotamicu) In: Aquaciência, 2., 2006, Bento Gonçalves. Anais... Bento Gonçalves: Aquabio, 2006. CD-ROM. (Resumo).

PRODUÇÃO animal, 2007. Brasília: Embrapa. Disponível em: <http://www.embrapa.br/>. Acessado em: 1 out. 2007. 
RAYMOND, M.; ROUSSET, F. An exact test for population differentiation. Evolution, v.49, p.1280-1283, 1995.

RECURSOS pesqueiros: Estatística pesqueira, 2005. Brasília: IBAMA. Disponível em: $<$ http://www.ibama.gov.br/>. Acessado em: 1 out. 2007.

ROHLF, F.J. NTSYS-Pc: Numerical taxonomy and multivariate analysis system. New York: Exeter, 1989.

SANTOS, M.C.F.; RUFFINO, M.L.; FARIAS, I.P. High levels of genetic variability panmixia of the Tambaqui Colossoma macropomum (Cuvier, 1816) in main channel of the Amazon River. J. Fish Biol., v.71, Suppl. A, p.33-44, 2007.

SEKINO, M.; SUGAYA, T.; HARA, M. et al. Relatedness inferred from microsatellite genotypes as a tool for broodstock management of Japanese flounder Paralichthys olivaceus. Aquaculture, v.233, p.163-172, 2004.

SIROL, R.N.; BRITTO, S.G. Conservação e manejo da ictiofauna: Repovoamento. In: NOGUEIRA, M.G.; HENRY, R.; JORCIN, A.
(Ed). Ecologia de reservatórios: Impactos potenciais, ações de manejo e sistemas em cascatas. São Carlos: RIMA, 2006, p.275-284.

STREIT Jr., D.P. Diagnóstico técnico das unidades produtoras de alevinos do estado de Rondônia. Porto Velho: EMATER, 2005. 45p.

WASKO, A.P.; MARTINS, C.; OLIVEIRA, C. et al. Genetic monitoring of the Amazonian fish matrinchã (Brycon cephalus) using RAPD markers: insights into supportive breeding and conservation programmes. J. Appl. Ichthyol., v.20, p.48-52, 2004.

WRIGHT, S. Evolution and genetics of populations. Chicago: University of Chicago Press, 1978. 511p.

YEH, F.C.; BOYLE, T.Y.Z.; XIYAN, J.M. POPGENE Version 131: Microsoft Windowbased freeware for population genetic analysis. Edmonton: University of Alberta and Center for International Forestry Research, 1999.

YOKOTA, M.; HARADA, Y.; IIZUKA, M. Genetic drift in a hatchery and the maintenance of genetic diversity in hatchery-wild systems. Fish. Sci., v.69, p.101-109, 2003. 